\title{
The Water Permeability Reduction After Successive Hypo-Osmotic Shocks in Kidney Principal Cells is Apically Regulated
}

\author{
Liubov E. Katkova ${ }^{a}$ Galina S. Baturina ${ }^{a}$ Alexander V. Ilyaskin ${ }^{a}$ \\ Sotirios G. Zarogiannis ${ }^{b}$ Evgeniy I. Solenov ${ }^{a, c}$ \\ anstitute of Cytology and Genetics, SB RAS, Novosibirsk, Russia, 'Department of Physiology, Medical \\ School, University of Thessaly, BIOPOLIS, Larissa, Greece, 'Novosibirsk State University, Novosibirsk, \\ Russia
}

\section{Key Words}

Aquaporins • Kidney • Principal cells • Regulatory Volume Decrease • Hypo-osmotic shock • Water permeability

\begin{abstract}
Background/Aims: Renal principal cells maintain their intracellular water and electrolyte content despite significant fluctuations of the extracellular water and salt concentrations. Their water permeability decreases rapidly (within a few seconds) after successive hypo-osmotic shocks. Our aim was to investigate the contribution of the apical and basolateral surface to this effect and the potential influence of fast reduction in AQP-2, -3 or -4 plasma membrane content. Methods: Rat principal cells of kidney collecting duct fragments underwent hypoosmotic challenge applied apically or basolaterally and the regulatory volume decrease (RVD) was measured by the calcein quenching method. The AQP $-2,-3$ and -4 content of the plasma membrane fraction was quantified by Western blotting. Results: The hypo-osmotic shock applied apically causes rapid swelling with high apparent water permeability and fast RVD. An identical successive shock after $15-20$ sec causes significantly lower swelling rate with 3-fold reduction in apparent water permeability. This reaction is accompanied by AQP2 decrease in the plasma membrane while AQP3 and AQP4 are unaffected. The contribution of the basolateral cell surface to RVD is significantly lower than the apical. Conclusion: These results indicate that in principal cells the effective mechanism of RVD is mainly regulated by the apical cell plasma membrane.
\end{abstract}

Copyright @ 2014 S. Karger AG, Basel

\section{Introduction}

In mammals the regulation of water and salt reabsorption in the kidney is a hallmark homoeostatic mechanism [1]. A key cell type in this process is the kidney collecting 
duct principal cell that has the ability to maintain its intracellular water and electrolyte content despite being exposed to significant fluctuations of extracellular water and salt concentrations [2]. Given that principal cells maintain their water and salt balance in an environment of steep osmotic pressures while significant amounts of reabsorbing ions and water pass through them, they are imposed to significant perturbations of their cell volume [1-3]. These are counterbalanced by two different mechanisms, the regulatory volume increase (RVI; when faced with hypertonic medium) and the regulatory volume decrease (RVD; when faced with hypotonic medium) [3].

In cases of exposure to hypotonic medium, as is the case in the Outer Medullary Collecting Duct (OMCD) epithelial cells that are in contact with tubular liquid at the beginning of the kidney counter current concentrating mechanism that has low osmotic concentration $(<200$ $\mathrm{mOsm} / \mathrm{kg}$ ), the driving force moving water inside the cell is the trans-membrane osmotic gradient [4-6]. In such a case the resulting cell swelling activates the mechanism of RVD. In RVD the cells return to their original volume through a complex mechanism that includes many-fold increases of the membrane permeability for $\mathrm{K}^{+}$, $\mathrm{Cl}^{-}$and organic anions $[4,6]$. In line with this, it has been demonstrated that compensatory reaction of RVD in hypotonic conditions is carried out via significant osmolytes release and subsequently accompanied by a decrease in the plasma membrane water permeability [7]. Therefore, in order for principal cells to produce an effective RVD response they have to adjust their ion and water permeability of the plasma membrane to the intensity of trans-cellular transport of water and osmolytes, which is a rapid effect [7].

Water permeability in the collecting duct (CD) is under hormonal control of vasopressin, the principal regulator of water reabsorption in kidney [8]. Vasopressin regulates the expression of the apically located AQP2 and may control the function of the basolaterally located AQP3 and AQP4 water channels [9-13]. The apical membrane that contains AQP2 is considered the main barrier for water permeability in principal cells [14]. Indeed, defective or de-regulated AQP2 production and recycling in principal cells is the source of serious clinical conditions such as nephrogenic diabetes insipidus, leading to excess loss of body water [15]. However, there is not enough evidence regarding the role of basolaterally located aquaporins, AQP3 and AQP4, in the principal cell water permeability as well as regarding their contribution to the water barrier effect. Lessons learned from transgenic mice show that AQP3 (which functions also as a glycerol transporter) knockouts have a threefold decrease in the basolateral osmotic water permeability resulting in severe polyuria and tenfold higher water intake while AQP4 knockouts exhibit a milder polyuria [16]. Finally double knockouts have more severe polyuria than AQP3 knockouts [16].

Therefore, the aim of this work was to investigate the effects of hypotonic shock in principal cells in terms of apical and basolateral surface contribution to RVD as well as to evaluate the role of aquaporin availability in the plasma membrane in this context.

\section{Materials and Methods}

Animals

All experimental procedures were approved by the Ethical Committee of the Institute of Cytology and Genetics of the Siberian Branch of the Russian Academy of Sciences. Wistar rats weighting 150-200 g (Breeding Laboratory of Experimental Animals, Institute of Cytology and Genetics, Novosibirsk, Russia) were kept in individual cages and received standard diet. For standardization of animals' state and increase of the osmotic water permeability of the OMCD epithelial cells prior to beginning of the experiments, rats were subjected to anti-diuresis by water deprivation and receiving only dry food for $36 \mathrm{~h}$ (hypo-hydrated animals). These animals had urine osmolality values in interval $2500-3000 \mathrm{mOsm} / \mathrm{kg}$.

Solutions

The solutions used were based on PBS ( $137 \mathrm{mM} \mathrm{NaCl}, 4.7 \mathrm{mM} \mathrm{Na}_{2} \mathrm{HPO}_{4}, 2.7 \mathrm{mM} \mathrm{KCl}, 1.5 \mathrm{mM} \mathrm{KH}_{2} \mathrm{PO}_{4^{\prime}}$ $0.5 \mathrm{mM} \mathrm{MgCl}, 1 \mathrm{mM} \mathrm{CaCl} ; 300 \mathrm{mOsm} / \mathrm{kg} \mathrm{H}_{2} \mathrm{O} ; \mathrm{pH}=7.4$ ) containing $1.0 \mathrm{mg} / \mathrm{mL}$ glucose. This solution was 


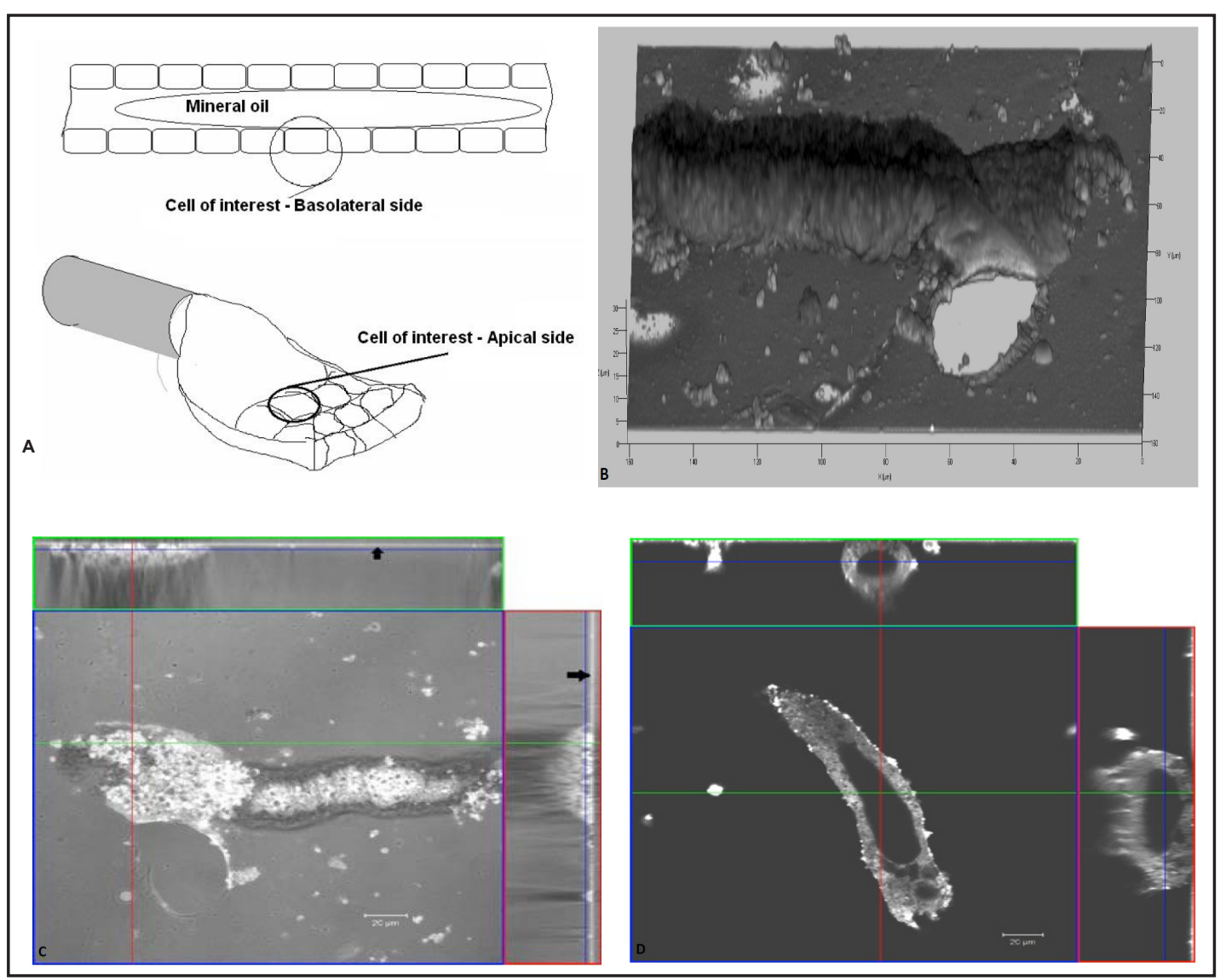

Fig. 1. Sample preparation. (A) Schematic of the orientation of the OMCD fragments used for the biophysical measurements of cell volume regulation. (B) OMCD fragments with the open apical surface in order to perform apical surface measurements of cell volume regulation. (C) Confocal image with 3D projections of OMCD fragments with the open apical surface in order to perform apical surface measurements of cell volume regulation. The arrows show the glass surface. Scale bar: $20 \mu \mathrm{m}$. (D) Confocal image with 3D projections of OMCD fragment loaded with oil droplet (volume around $10 \mathrm{~nL}$ ) in order to perform basolateral surface measurements of cell volume regulation. Scale bar: $20 \mu \mathrm{m}$.

chosen in order to be able to degas it without affecting its $\mathrm{pH}$. To create hypotonic challenges, bath solutions were changed from normal to PBS diluted with distilled water (1:1). Two successive hypotonic challenges were performed with a lag-time of around $20 \mathrm{sec}$. For medullary substance dispersion calcium-free PBS was used (137 mM NaCl, $4.7 \mathrm{mM} \mathrm{Na}_{2} \mathrm{HPO}_{4}, 2.7 \mathrm{mM} \mathrm{KCl}, 1.5 \mathrm{mM} \mathrm{KH}_{2} \mathrm{PO}_{4}, 0.5 \mathrm{mM} \mathrm{MgCl}, 0.05 \mathrm{mM} \mathrm{CaCl}_{2}$ ).

\section{Preparation of collecting duct fragments}

Rats were anesthetized by pentobarbital $(50 \mathrm{mg} / \mathrm{kg}$ intraperitoneally) and decapitated. Extracted kidneys were placed in ice-cold PBS, then de-capsulated and de-corticated. A suspension of collecting duct fragments was prepared. Tissue from the outer medulla zone was squeezed through a needle $(0.45 \mathrm{~mm}$ i.d.) in the ice-cold calcium-free PBS. The resulting suspension was filtered through a nylon mesh, diluted 10 times with Eagle MEM culture medium and centrifuged (100 g, $\left.10 \mathrm{~min}, 4^{\circ} \mathrm{C}\right)$. The sediment containing the tubules was diluted with culture medium to an appropriate concentration of about 10 fragments per $\mu \mathrm{L}$. This suspension was used in experiments as a preparation of OMCD fragments. In the experiments with hypotonic shock, the suspension of the OMCD fragments was incubated in $0.5 \mathrm{x}$ PBS at $37^{\circ} \mathrm{C}$ during 3 min. In the experiments where either the apical or the basolateral cell surface was studied, an OMCD fragment was chosen according to morphological criteria, and an oil droplet with typical volume range 5.0-10.0 nL was injected into the lumen using a glass micropipette [9]. Two experimental preparations were used for our studies (Fig. 1A): a) Fragments that were cut open with a glass needle and subsequently unfolded, 
Fig. 2. Experimental instrumentation. Schematic depicting the experimental instrumentation used for the biophysical measurements of the relative cell volume changes after successive hypo-osmotic shocks. Insert: (1) Poly-D-lysine coated coverglass with immobilized OMCD fragment. (2) Acrylic block with silicone 0ring sealing. (3) Input of medium current in the OMCD fragment area. (4) Output of medium current from the OMCD fragment area. (5) Microscope lens.

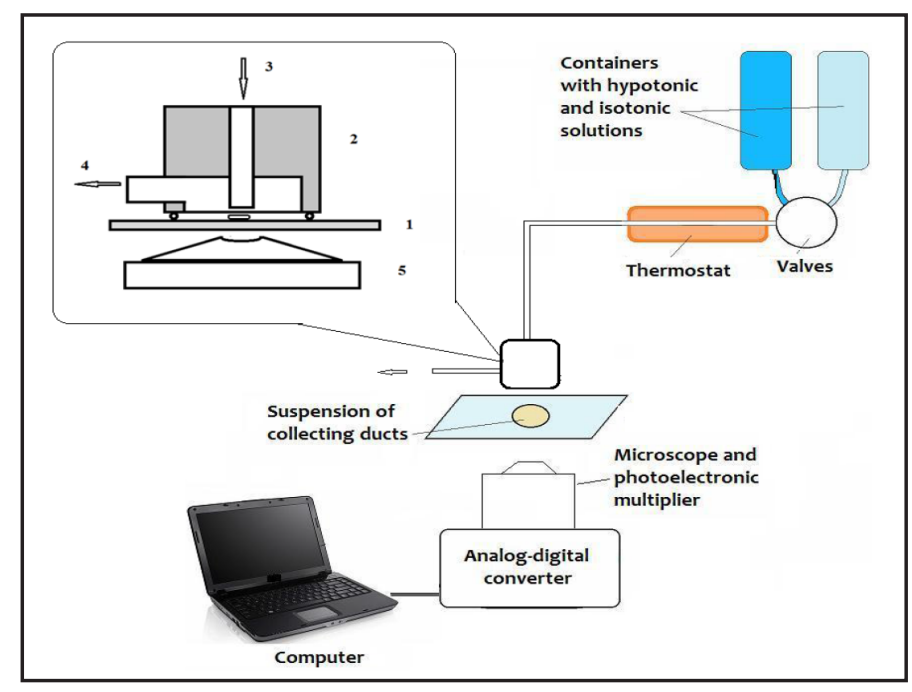

whose principal cells contacted with the bathing medium only by their apical surface, $b$ ) Fragments whose cells contacted with the bathing medium only by their basolateral surface while their apical surface was covered with oil. The OMCD fragments with the open apical surface were imaged by a scanning confocal microscope as shown in Fig. 1B and Fig. 1C (Zeiss LSM-780, oil immersion objective lens 63x, Numerical aperture 1.4, Zeiss, Germany). The OMCD fragments with the oil droplet were imaged by a scanning confocal microscope as shown in Fig. 1D (Zeiss LSM-780, oil immersion objective lens 63x, Numerical aperture 1.4, Zeiss, Germany).

\section{Perfusion chamber and microscopy}

A superfusion chamber was constructed as an acrylic block with a T-shape design for perfusion medium. This design enables the fast exchange of perfusion medium in the proximal area around the fragment and prevents the disturbance of the specimen. The flow rate of the perfusate was $20 \mathrm{~mL} / \mathrm{min}$, which resulted in complete solution exchange in the area of interest in less than $100 \mathrm{~ms}$. The chamber was mounted on the stage of an inverted microscope (Axiovert 40, Zeiss, Germany; objective lens with 40x magnification; numerical aperture 0.65 ; thermal stabilization at $36.8 \pm 0.2^{\circ} \mathrm{C}$ ). The temperature was chosen so as to provide adequate functional conditions for all transporters and to prevent inhibition of transporters with high energy of activation that could occur at low temperatures. Fluorescence measurements of cell volume were performed by the calcein quenching method as it was previously described $[7,17]$. The changes of the cell volume in the hypertonic medium were expressed as relative cell volume changes (V/ $\left.\mathrm{V}_{0}\right)$. Relative values of calcein fluorescence $\left(\mathrm{F} / \mathrm{F}_{0}\right)$ corresponded to $\mathrm{V} / \mathrm{V}_{0}$, serving as a surrogate of the cell volume fluctuations [7]. Fragments of the OMCD were placed on a glass plate and were loaded with CalceinAM (Invitrogen, CA, USA; $5 \mu \mathrm{M}, 15-\mathrm{min} 37^{\circ} \mathrm{C}$ ). The fluorescence of calcein was continuously measured with a halogen light source, through a filter set \#09 (BP 450 - $490 \mathrm{~nm}$ excitation, FT $510 \mathrm{~nm}$ dichroic mirror, LP $515 \mathrm{~nm}$ emission), a photomultiplier detector with a pinhole diaphragm in order to be able to select the cells of interest and with a 14-bit analog-to-digital converter PCL-818HG (Advantech). Data acquisition rate was set to $10 \mathrm{msec}$. The experimental procedure is summarized in Fig. 2.

\section{Preparation of plasma membrane enriched fraction and western blot analysis}

Specimens of Outer Medulla were cut to slices 100-150 $\mu \mathrm{m}$ thick. The control slices (normotonic) were incubated in PBS with osmotic concentration of $300 \mathrm{mOsm} / \mathrm{kg} \mathrm{H}_{2} \mathrm{O}$. The test sample slices (hypotonic) were placed initially in PBS with osmotic concentration of $300 \mathrm{mOsm} / \mathrm{kg} \mathrm{H}_{2} \mathrm{O}$ and subsequently subjected to hypotonic challenge in $0.5 \mathrm{X}$ PBS $\left(150 \mathrm{mOsm} / \mathrm{kg} \mathrm{H}_{2} \mathrm{O}\right)$. The incubation was performed at $37^{\circ} \mathrm{C}$ for $3 \mathrm{~min}$. Immediately after the tissue was homogenized in a glass homogenizer, in ice cold homogenizing buffer (HB) (10 mM Tris-Cl pH 7.4, $0.25 \mathrm{M}$ sucrose, $1 \mathrm{mM}$ EDTA, $10 \mathrm{mM} \beta$-mercaptoethanol) containing a mixture of protease inhibitors (Complete protease inhibitor tablete, Santa Cruz). Cell debris was removed after centrifugation (2000 rpm for $15 \mathrm{~min}$ at $4^{\circ} \mathrm{C}$ ). Percoll (Pharmacia, Sweden) was added to the supernatant to $30 \%$ (final concentration) and the mixture was centrifuged for $45 \mathrm{~min}$ at $84000 \mathrm{~g}$ at $4^{\circ} \mathrm{C}[9,18]$. The 
Katkova et al.: Apical Regulation of Principal Cell $P_{f}$

membrane-rich fraction was collected and diluted with ice-cold HB buffer up to 5 times and centrifuged at $10000 \mathrm{~g}$ for $2 \mathrm{~h}$ at $4^{\circ} \mathrm{O}$. Pellet was resuspended in $100 \mu \mathrm{l}$ of homogenate buffer and stored at $-20^{\circ} \mathrm{C}$. The degree of enrichment was established by the evaluation of Na,K-ATPase expression by Western-blot (data not shown; antibodies from Santa Cruz, USA). The degree of enrichment was 1.8-2.0-fold compared to homogenate and 1.3-1.4-fold compared to the crude membrane fraction. Protein concentrations were determined by the Bradford assay (Bio-Rad, USA).

The sample was dissolved in homogenizing buffer containing 1\% SDS and applied on Laemmle PAAGE (15\% PAA separating gel). Proteins were transferred on PVDF membranes. The membranes were blocked with 5\% milk and sequentially incubated with primary antibodies against AQP2 (1:2000, Abcam, UK), AQP3 (1:2000, Chemicon, USA), AQP4 (1:2000, Millipore, USA), $\beta$-tubulin (1:10000 Abcam, UK), and horseradish peroxidase-conjugated goat anti-rabbit secondary antibodies (1:10000, Santa Cruz Biotechnology, USA). Immunoreactive bands were visualized by chemiluminescence using Western Blotting Luminol Ragent (Santa Cruz Biotechnology, USA) and detection on UltraCruz ${ }^{\mathrm{TM}}$ Autoradiography Film (Santa Cruz Biotechnology, USA).

Calculation of osmotic water permeability parameter (Pf)

The water permeability was determined from the rate of cell volume changes under osmotic challenge on the base of the equation:

$$
\frac{d V}{d t}=-A V_{W} P_{f} \nabla \Phi ;[7,19]
$$

The plasma membrane osmotic water permeability coefficient (Pf) was calculated from the time course of the volume change in response to an osmotic gradient. Osmotic water movement is the net flow of volume across a membrane in response to a hydrostatic and/or osmotic pressure:

$J=-L_{p} A \Delta \Phi ;$ or $d V / d t=-P A V_{w} \Delta C$

The permeability coefficient of the basolateral surface of the epithelium can be calculated from the slope $\left(\mathrm{K}_{\mathrm{r}}\right)$ of the linear plot:

$P_{f}=K_{r}\left[A V_{w}\left(C_{\text {in }}-C_{\text {out }}\right)\right]^{-1}[9]$

Where: $J$ is the rate of volume flow across the membrane $\left(\mathrm{cm}^{3} \mathrm{~s}^{-1}\right),(\mathrm{dV} / \mathrm{dt})$ is the rate of cell volume change, Lp is hydraulic conductivity $\left(\mathrm{cm}^{3} \mathrm{~s}-1 \mathrm{~atm}^{-1}\right)$, Pf is the osmotic water permeability coefficient $\left(\mathrm{cm} \mathrm{s}^{-1}\right)$, A is the surface area $\left(\mathrm{cm}^{2}\right)$ which is significant for water exchange, $\Delta \Phi$ is the osmotic pressure difference (atm), $\Delta \mathrm{C}$ is the osmotic concentration difference $\left(\mathrm{osm} \mathrm{kg}{ }^{-1}\right)$, and $\mathrm{V}_{\mathrm{w}}$ is the partial molar volume of water.

\section{Statistics}

Averaged experimental measurements were presented as mean value and standard error of mean $(\mathrm{M} \pm \mathrm{SEM})$. In Western blot analysis, $\mathrm{n}=$ blots (1 blot/animal); In biophysical experiments $\mathrm{n}=$ OMCD fragments ( 3 fragments/animal). Normality test was performed with the Kolmogorov-Smirnov test and statistical significance was evaluated with unpaired two-tailed t-test. Values that had a $p<0.05$ were deemed statistically significant.

\section{Results}

The water permeability of the apical surface of OMCD principal cells is significantly reduced after a hypo-osmotic shock

Preparations of OMCD whose apical surface was exposed, underwent two successive hypo-osmotic shocks in order to assess the apical contribution of water permeability in the RVD reaction. To this end, OMCD principal cells whose apical surface was exposed underwent hypo-osmotic shock by a rapid switch from normo-osmotic (300 mOsm/ $\mathrm{kg} \mathrm{H}_{2} \mathrm{O}$ ) to hypoosmotic medium (150 mOsm/ $\left.\mathrm{kg} \mathrm{H}_{2} \mathrm{O}\right)$. Subsequently the medium was switched for another cycle in a similar manner resulting in two successive hypo-osmotic shocks. Linear regression analysis of the swelling kinetics provides the basis for the calculation of the total water flux into the cell and the evaluation of the apparent water permeability of the plasma membrane. As shown in Fig. 3A there was a significantly 3-fold decreased osmotic water permeability 


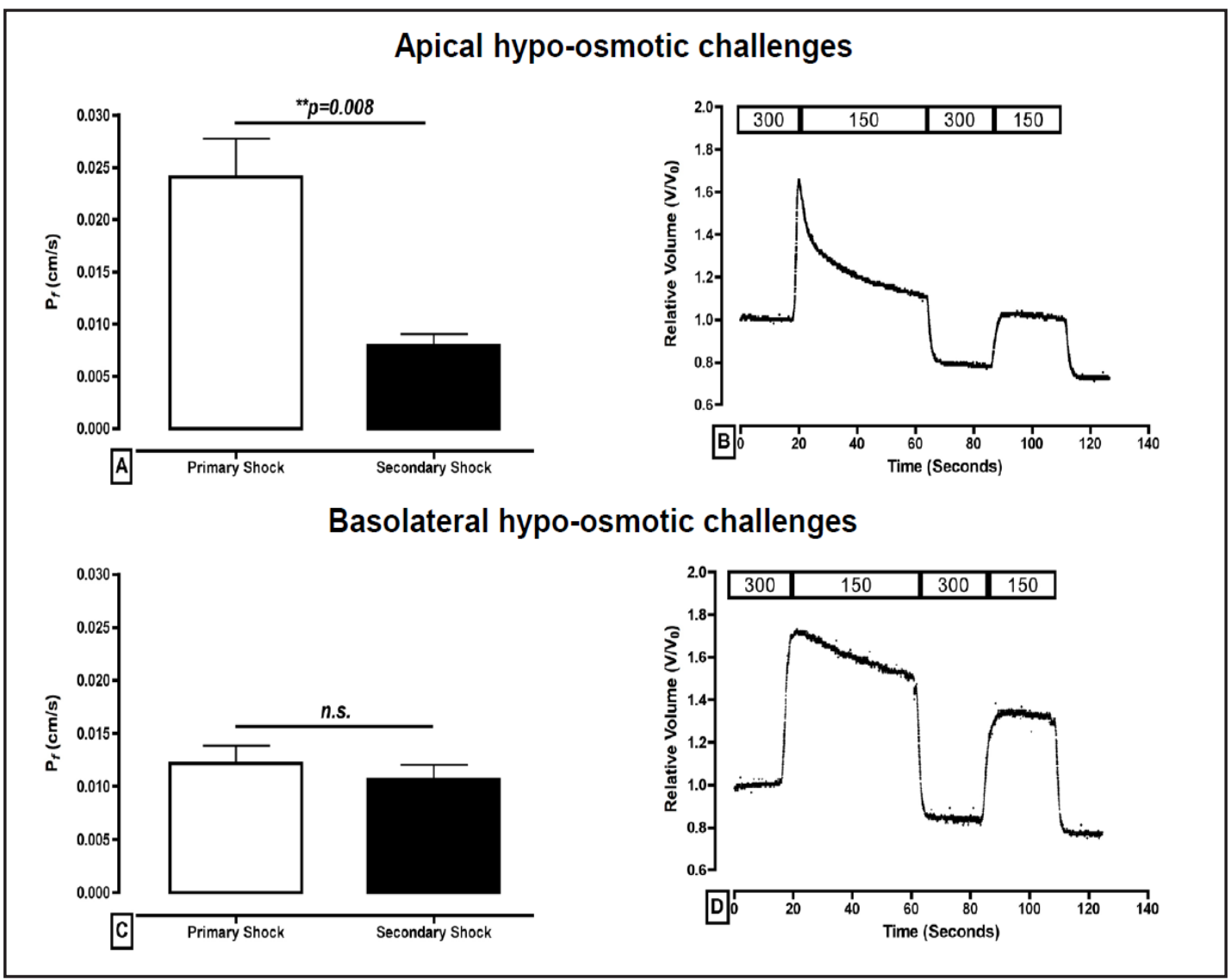

Fig. 3. Osmotic water permeability of apical and basolateral surface of renal OMCD principal cells in the course of two consecutive hypo-osmotic shocks. (A) Osmotic water permeability $\left(P_{f_{i}} \mathrm{~cm} / \mathrm{s}\right)$ after apical hypoosmotic challenges $(\mathrm{M} \pm \mathrm{SEM} ; n=6)$. (B) Typical experiment of the relative cell volume $\left(\mathrm{V} / \mathrm{V}_{0}\right)$ after apical hypo-osmotic challenges. (C) Osmotic water permeability $\left(P_{f ;} \mathrm{cm} / \mathrm{s}\right)$ after basolateral hypo-osmotic challenges $(\mathrm{M} \pm \mathrm{SEM} ; n=11)$. (D) Typical experiment of the relative cell volume $\left(\mathrm{V} / \mathrm{V}_{0}\right)$ after basolateral hypo-osmotic challenges. The top scales in B and D represent the changes of the osmolarity of the extracellular medium in mOsm $/ \mathrm{kg} .{ }^{*} p<0.05$ considered significant.

coefficient $\left(P_{f}\right)$ in the second shock $\left[0.024 \pm 0.004\right.$ vs. $0.008 \pm 0.001 \mathrm{~cm} / \mathrm{s} ;{ }^{* *} p=0.008 ; \mathrm{n}=6$ in both cases]. A typical experimental curve is shown in Fig. 3B where fast swelling and subsequent RVD reaction is shown initially (rapid increase in the apical swelling rate after the first shock) and the significantly reduced RVD reaction (thus reduced swelling rate) after the second shock is shown.

The water permeability of the basolateral surface of OMCD principal cells is unaffected by successive hypo-osmotic shocks

Preparations of fragments of OMCD whose lumen was loaded with a droplet of mineral oil so that only the basolateral surface would be exposed to the experimental medium, underwent two successive hypo-osmotic shocks in order to assess the basolateral contribution of water permeability in the RVD reaction. The experimental conditions were the same as in the case of apical hypo-osmotic shock. As shown in Fig. 3C there was no difference in the osmotic water permeability coefficient $\left(P_{f}\right)$ between the first and second hypo-osmotic shocks $[0.012 \pm 0.002$ vs. $0.011 \pm 0.001 \mathrm{~cm} / \mathrm{s} ; p=n . s$.; $\mathrm{n}=11$ in both cases]. A typical experimental curve is shown in Fig. 3D where similar swelling and subsequent RVD reactions are shown in the first and second shock. 


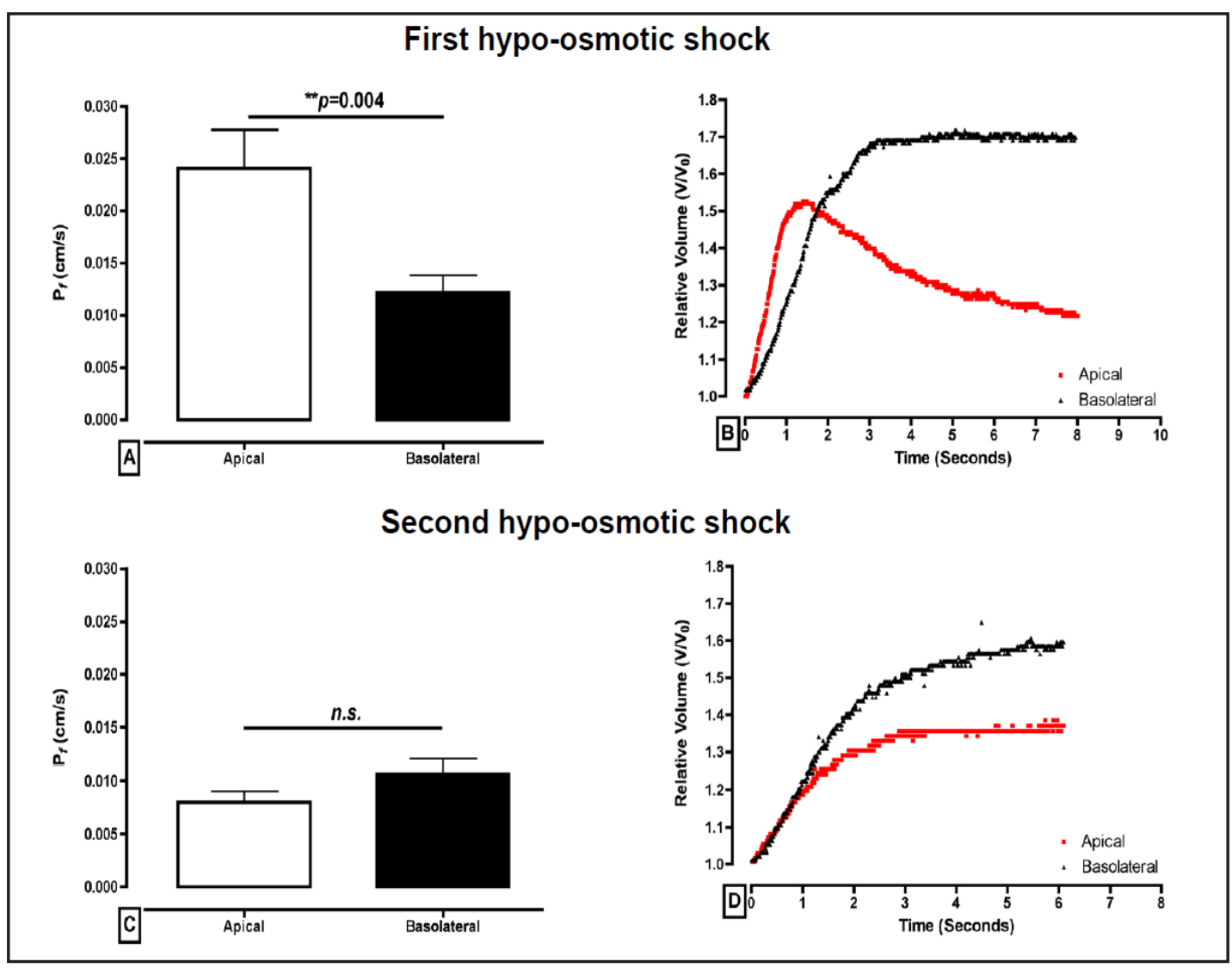

Fig. 4. Comparisons of the osmotic water permeability during the first and seconds shocks in the apical and basolateral surfaces of renal OMCD principal cells. (A) Osmotic water permeability $\left(P_{f ;} \mathrm{cm} / \mathrm{s}\right)$ after the first hypo-osmotic challenge ( $\mathrm{M} \pm \mathrm{SEM} ; n=6$ apical and $n=11$ basolateral). (B) Comparison of typical experimental curves of the relative cell volume $\left(\mathrm{V} / \mathrm{V}_{0}\right)$ after the first hypo-osmotic challenges. (C) Osmotic water permeability $\left(P_{f_{i}} \mathrm{~cm} / \mathrm{s}\right)$ after the second hypo-osmotic challenge (M \pm SEM; $n=6$ apical and $n=11$ basolateral). (D) Comparison of typical experimental curves of the relative cell volume $\left(\mathrm{V} / \mathrm{V}_{0}\right)$ after the second hypo-osmotic challenges. ${ }^{*} p<0.05$ considered significant.

The water permeability of the apical surface of OMCD principal cells is significantly higher than that of the basolateral

A comparison of the $P_{f}$ of the apical and basolateral surfaces of the OMCD principal cells with respect to the first and second hypo-osmotic shock reveals that the apical $P_{f}$ is significantly higher than the basolateral in the first shock $[0.024$ 0.004 vs. $0.012 \pm 0.002 \mathrm{~cm} / \mathrm{s} ;{ }^{* *} p=0.004 ; \mathrm{n}=11$ and 6 respectively; Fig. $\left.4 \mathrm{~A}\right]$ and there is no significant difference in the second shock [0.011 \pm 0.001 vs. $0.008 \pm 0.001 \mathrm{~cm} / \mathrm{s} ; p=n . s . ; \mathrm{n}=11$ and 6 respectively; Fig. 4C]. In Fig. 4B and 4D, representative slopes of the relative volume increase in the first and second hypo-osmotic shocks in the apical and basolateral surface are shown respectively.

The significant apical reduction in Pf is associated with a reduction in the AQP2 plasma membrane availability after the first hypo-osmotic shock

Fractions of the plasma membrane of preparations that underwent hypo-osmotic shock were probed for AQP2 (located mainly in the apical surface of OMCD principal cells) and AQP3 and AQP4 (located mainly in the basolateral surface of OMCD principal cells) in order to reveal whether a change in the plasma membrane content may be responsible for the reduction in $P_{f}$ In Fig. 5 it is evident that there is a significant reduction in the content of AQP2 (Fig. 5A and D) in the plasma membrane while AQP3 (Fig. 5B and D) and AQP4 (Fig. 


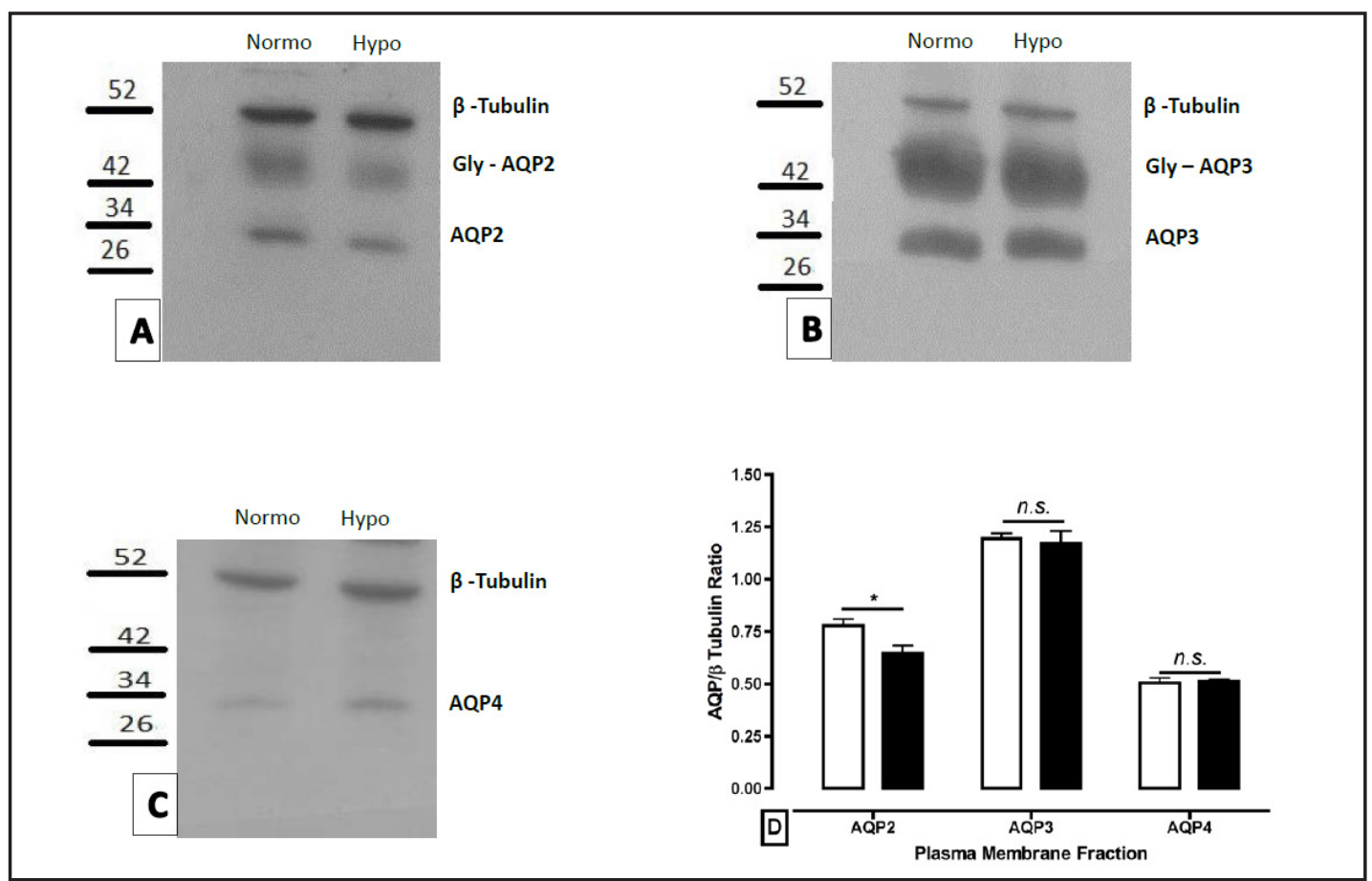

Fig. 5. Comparison of plasma membrane fractions of aquaporins. (A) Western Blot analysis of plasma membrane fraction of AQP2, glycosylated AQP2 and $\beta$-tubulin in OMCD fragments after hypo-osmotic shock for 3 min. Normo: $300 \mathrm{mOsm} / \mathrm{kg} \mathrm{H}_{2} \mathrm{O}$; Hypo: $150 \mathrm{mOsm} / \mathrm{kg} \mathrm{H}_{2} \mathrm{O} .50 \mu \mathrm{g}$ of protein were loaded per lane. B-tubulin was examined as a loading control. (B) Western Blot analysis of plasma membrane fraction of AQP3, glycosylated AQP3 and $\beta$-tubulin in OMCD fragments after hypo-osmotic shock for $3 \mathrm{~min}$. Normo: $300 \mathrm{mOsm} / \mathrm{kg}$ $\mathrm{H}_{2} \mathrm{O}$; Hypo: $150 \mathrm{mOsm} / \mathrm{kg} \mathrm{H}_{2} \mathrm{O} .50 \mu \mathrm{g}$ of protein were loaded per lane. B-tubulin was examined as a loading control. (C) Western Blot analysis of plasma membrane fraction of AQP4 and $\beta$-tubulin in OMCD fragments after hypo-osmotic shock for 3 min. Normo: $300 \mathrm{mOsm} / \mathrm{kg} \mathrm{H}_{2} \mathrm{O}$; Hypo: $150 \mathrm{mOsm} / \mathrm{kg} \mathrm{H}_{2} \mathrm{O} .50 \mu \mathrm{g}$ of protein were loaded per lane. B-tubulin was examined as a loading control. (D) Densitometric analysis between Normo and Hypo for every AQP tested. White columns: Normotonic medium, Black columns: Hypotonic medium. Image analysis was performed with ImageJ software. ${ }^{*} p<0.05$ considered significant.

$5 \mathrm{C}$ and $\mathrm{D}$ ) remain unaffected. Indeed there was a statistically significant difference between the AQP2/beta-Tubulin ratio ( $0.78 \pm 0.03$ vs. $0.65 \pm 0.04 ;{ }^{*} p=0.011 ; n=9$ in both cases; Fig. 5D).

\section{Discussion}

We have previously shown in our ex-vivo model of successive hypo-osmotic shocks in OMCD principal cells that after the first shock where the RVD mechanism is rapid, their water permeability decreases significantly [7]. We postulated that our finding reflected the cell adaptation after the first hypotonic shock leading to cell integrity protection. Moreover, our finding was in agreement with in vitro published data regarding the reduction of AQP2 translocation to the apical cell surface under hypotonic challenge as a means of protection form excess swelling [20].

In this study we aimed at elucidating the physiological characteristics of this cell response at the tissue level in more depth by assessing the contribution of the apical and basolateral cell surfaces. We demonstrate that the rapid cell swelling occurring in OMCD principal cells that undergo hypo-osmotic shock is mainly mediated by the high osmotic water permeability of the apical cell surface while the basolateral surface has significantly lower osmotic water permeability. On the other hand, when an identical hypo-osmotic shock 
is applied after 10-15 seconds the osmotic water permeability of both surfaces is equally low. In order to address the mechanism responsible for these observations we assessed the content of AQP-2, AQP-3 and AQP-4 in the fraction of the plasma membrane. Our finding was that although the levels of AQP3 and AQP4 remain unaffected by the hypo-osmotic shock, the levels of AQP2 are significantly reduced. Given that renal principal cells express three types of AQP's, AQP2 apically and AQP3/AQP4 basolaterally [21], our finding partially explains how the high apical osmotic water permeability is significantly reduced after the first hypoosmotic shock. Indeed, in our previous work we had concluded from our modeling data that after the first shock the intracellular amounts of $\mathrm{Na}+, \mathrm{K}+$ and organic anions are reduced by $50 \%$ indicating that the main body of osmolyte loss occurs predominantly under the first osmotic challenge [7].

To our knowledge, this is the first experimental proof that provides the basis to consider the RVD as a mechanism bound to the apical surface of the renal principal cell investigating repeated shocks $[7,22]$. Due to the sub-second resolution of our method we cannot compare our findings directly with the available literature since both experimental and theoretical approaches involve slow exchange processes or steady state modeling [23-26]. However, as far as the trafficking of AQP2 is concerned it has already been reported in CD8 cells (in vitro system as opposed to our ex vivo system) that hypotonic challenge induces internalization of AQP2 [20]. Our results verify that this is the case even in a more complex system such as the fragments of OMCD's and furthermore pose the need for a mechanistic understanding of this fast AQP2 internalization phenomenon. It has already been described that the activation of $\mathrm{PKC}$ induces the mono-ubiquitination of AQP2 at the K270 in vitro and ex vivo leading to the endocytosis of AQP2 [27]. However, the fact that this PKC activation was observed at a time point much later than the one we observe our effect, cannot explain the rapid decrease in the osmotic water permeability observed in our preparation. Therefore, more in depth studies of the fast endocytosis of AQP2 are needed to explain the effect reported here because it may be that the mechanism controlling the function of AQP2 includes both internalization as well as gating regulation. The finding that $\mathrm{AQP} 2$ phosphorylation by PKA in an artificial system (reconstituted liposomes) has been shown to enhance its water permeability is supportive of the notion involving gating of AQP2 [28]. Finally, the role of cytoskeletal involvement in these rapid functions has to be also considered since caveolin-1 is associated with AQP2 internalization procedure [29]. Actin filaments take part in the trafficking of AQP2 while increasing the cell water permeability in response to vasopressin [30]. On this basis, it can be postulated that the cytoskeleton may play a role in the down regulation of these channels during cell swelling in hypotonic medium.

\section{Acknowledgements}

This work was supported by RFBR grants (14-04-31258, 12-04-00369, 12-04-00370, 12-04-31298).

\section{Disclosure Statement}

The authors of this manuscript have nothing to disclose.

\section{References}

1 Hoffmann E, Lambert I, Pedersen S: Physiology of Cell Volume Regulation in Vertebrates. Physiol Rev 2009;89:193-277.

Karet FE: Disorders of water and acid-base homeostasis. Nephron Physiol 2011;118:28-34.

Lang F, Busch GL, Ritter M, Volkl H, Waldegger S, Gulbins E, Haussinger D: Functional Significance of Cell

Volume Regulatory Mechanisms. Physiol Rev 1998;78:247-306.

4 Strange K: Cellular volume homeostasis. Adv Physiol Edu 2004;28:155-159. 


\section{Cellular Physiology $\quad$ Cell Physiol Biochem 2014;34:1802-1811 and Biochemistry \\ Katkova et al.: Apical Regulation of Principal Cell $P_{f}$}

5 Gottschalk CW, Mylle M: Micropuncture study of the mammalian urinary concentrating mechanism: evidence for the countercurrent hypothesis. Am J Physiol 1959;196:927-936.

-6 Ilyaskin AV, Karpov DI, Medvedev DA, Ershov AP, Baturina GS, Katkova LE, Solenov EI: Quantitative estimation of transmembrane ion transport in rat renal collecting duct principal cells. Gen Physiol Biophys 2014;33:13-28.

7 Zarogiannis SG, Ilyaskin AV, Baturina GS, Katkova LE, Medvedev DA, Karpov DI, Ershov AP, Solenov EI: Regulatory volume decrease of rat kidney principal cells after successive hypo-osmotic shocks. Math Biosci 2013;244:176-187.

8 Pedersen SF, Kapus A, Hoffman EK: Osmosensory Mechanisms in Cellular and Systemic Volume Regulation. J Am Soc Nephrol 2011;22:1587-1597.

-9 Solenov EI, Nesterov VV, Baturina GS, Khodus GR, Ivanova LN: Effect of dAVP on basolateral cell surface water permeability in the outer medullary collecting duct. Eur Biophys J 2003;32:614-619.

10 Sasaki S, Ishibashi K, Marumo F: Aquaporin-2 and-3: Representatives of Two Subgroups of the Aquaporin Family Colocalized in the Kidney Collecting Duct. Annu Rev Physiol 1998;60:199-220.

-11 Schenk LK, Bolger SJ, Luginbuhl K, Gonzales PA, Rinschen MM, Yu MJ, Hoffert JD, Pisitkun T, Knepper MA: Quantitative Proteomics Identifies Vasopressin-Responsive Nuclear Proteins in Collecting Duct Cells. J Am Soc Nephrol 2012;23: 1008-1018.

12 Ecelbarger CA, Terris J, Frindt G, Echevarria M, Marples D, Nielsen S, Knepper MA: Aquaporin-3 water channel localization and regulation in rat kidney. Am J Physiol 1995;269:663-672.

13 Marlar S, Arnspang EC, Koffman JS, Løcke EM, Christensen BM, Nejsum LN: Elevated cAMP increases aquaporin-3 plasma membrane diffusion. Am J Physiol Cell Physiol 2014;306:598-606.

14 Wilson LLJ, Miranda CA, Knepper MA: Vasopressin and the regulation of aquaporin-2. Clin Exp Nephrol 2013;17:751-764.

15 Sasaki S: Aquaporin 2: From its discovery to molecular structure and medical implications. Mol Aspects Med 2012;33:535-546.

16 Verkman AS: Dissecting the roles of aquaporins in renal pathophysiology using transgenic mice. Semin Nephrol 2008;28:217-226.

17 Solenov E, Watanabe H, Manley GT, Verkman AS: Sevenfold-reduced osmotic water permeability in primary astrocyte cultures from AQP-4 deficient mice, measured by a fluorescence quenching method. Am J Physiol Cell Physiol 2004;286:426-432.

18 Oh P, Schitzer JE: Segregation of Heterotrimeric G Proteins in Cell Surface Microdomains. Mol Biol Cell 2001;12:685-698.

19 Jin BJ, Zhang H, Binder DK, Verkman AS: Aquaporin-4-dependent K+ and water transport modeled in brain extracellular space following neuroexcitation. J Gen Physiol 2013;141:119-132.

20 Tamma G, Procino G, Strafino A, Bononi E, Meyer G, Paulmichi M, Formoso V, Svelto M, Valenti G: Hypotonicity Induces Aquaporin-2 Internalization and Cytosol-to-Membrane Translocation of ICln in Renal Cells. Endocrinology 2007;148:1118-1130.

21 Nielsen S, Frokiaer J, Marples D, Kwon TH, Agre P, Knepper MA: Aquaporins in the kidney: from molecules to medicine. Physiol Rev 2002;82:205-244.

22 Solenov EI: Cell volume and sodium content in rat kidney collecting duct principal cells during hypotonic shock. J Biophys 2008;2008:420963.

23 Hernandez JA, Chifflet S: Electrogenic properties of the sodium pump in a dynamic model of membrane transport. J Membr Biol 2000;176:41-52.

24 Weinstein AM: Modeling epithelial cell homeostasis: Steady-state analysis. Bull Math Biol 1999;61:10651091.

25 Ford P, Rivarola V, Chara O, Blot-Chabaut M, Cluzeaud F, Farman N, Parisi M, Capurro C: Volume regulation in cortical collecting duct cells: Role of AQP2. Biol Cell 2005;97;687-697.

-26 Di Giusto G, Flamenco P, Rivarola V, Fernandez J, Melamud L, Ford P, Caporr C: Aquaporin-2 increased renal cell proliferation is associated with cell volume regulation. J Cell Biochem 2012;113:3721-3729.

27 Kamsteeg EJ, Hendriks G, Boone M, Konings IB, Oorschot V, van der Sluijs P, Klumperman J, Deen PM: Shortchain ubiquitination mediates the regulated endocytosis of the aquaporin-2 water channel. Proc Natl Acad Sci USA 2006;103: 18344-18349.

28 Eto K, Noda Y, Horikawa S, Uchida S, Sasaki S: Phosphorylation of aquaporin-2 regulates its water permeability. J Biol Chem 2010;285:40777-40784.

29 Aoki T, Suzuki T, Hagiwara H, Kuwahara M, Sasaki S, Takata K, Matsuzaki T: Close Association of Aquaporin-2 Internalization with Caveolin-1. Acta Histochem Cytochem 2012;45:139-146.

- 30 Jang KJ, Cho KS, Kang DH, Bae WG, Kwon TH, Suh KW: Fluid-shear-stress induced translocation of aquaporin-2 and reorganization of actin cytoskeleton in renal tubular epithelial cells. Integr Biol 2011;3:134-141. 